Research Paper

\title{
Earliest Bedside Assessment of Hemodynamic Param- eters and Cardiac Biomarkers: Their Role as Predictors of Adverse Outcome in Patients with Septic Shock
}

\author{
Benjamin Sasko ${ }^{\bowtie}$, Thomas Butz, Magnus Wilhelm Prull, Jeanette Liebeton, Martin Christ, Hans-Joachim
} Trappe

Department of Cardiology, Ruhr University Bochum, Marien Hospital Herne, Herne, Germany

$\square$ Corresponding author: Dr. med. Benjamin Sasko, Ruhr University Bochum, Department of Cardiology, Marien Hospital Herne, Hölkeskampring 40, 44625 Herne, Germany

(c) 2015 Ivyspring International Publisher. Reproduction is permitted for personal, noncommercial use, provided that the article is in whole, unmodified, and properly cited. See http://ivyspring.com/terms for terms and conditions.

Received: 2015.01.28; Accepted: 2015.07.07; Published: 2015.08.05

\begin{abstract}
Background: Early assessment and aggressive hemodynamic treatment have been shown to increase the survival of patients in septic shock. Current and past sepsis guidelines recommend a resuscitation protocol including central venous pressure (CVP), mean arterial blood pressure (MAP), urine output and central venous oxygen saturation $\left(\mathrm{ScrO}_{2}\right)$ for resuscitation within the first six hours. Currently, the established severity score systems like APACHE II score, SOFA score or SAPS II score predict the outcome of critically ill patients on the bases of variables obtained only after the first 24 hours. The present study aims to evaluate the risk of short-term mortality for patients with septic shock by the earliest possible assessment of hemodynamic parameters and cardiac biomarkers as well as their role for the prediction of the adverse outcome.

Methods: 52 consecutive patients treated for septic shock in the intensive care unit of one centre (Marien Hospital Herne, Ruhr University Bochum, Germany) were prospectively enrolled in this study. Hemodynamic parameters (MAP, CVP, $\mathrm{ScvO}_{2}$, left ventricular ejection fraction, Hematocrit) and cardiac biomarkers (Troponin I) at the ICU admission were evaluated in regard to their influence on mortality. The primary endpoint was all-cause mortality within 28 days after the admission.

Results: A total of 52 patients ( 31 male, 21 female) with a mean age of $71.4 \pm 8.5$ years and a mean APACHE II score of $37.0 \pm 7.6$ were enrolled in the study. 28 patients reached the primary endpoint (mortality 54\%). Patients presenting with hypotension (MAP $<65 \mathrm{mmHg}$ ) at ICU admission had significantly higher rates of 28-day mortality as compared with the group of patients without hypotension (28-day mortality rate $74 \%$ vs. $32 \%, p<0.01$ ). Furthermore, the patients in the hypotension present group had significantly higher lactate concentration $(p=0.002)$, higher serum creatinin $(p=0.04)$, higher NTproBNP $(p=0.03)$ and after the first 24 hours higher APACHE II scores $(p=0.04)$. A MAP $<65 \mathrm{mmHg}$ was the only hemodynamic parameter significantly predicting the primary endpoint (OR: 4.1, Cl: $1.1-14.8, p=0.008)$, whereas the remaining hemodynamic variables $\mathrm{CVP}, \mathrm{ScVO}_{2}$, Hematocrit, Troponin I and left ventricular ejection fraction (LVEF) seemed to have no influence on survival. Besides, non-survivors had a significantly higher age $(74.1 \pm 9.0 \mathrm{vs}$. $68.4 \pm 6.9, p=0.01)$. If hypotension coincided with an age $\geq 72$ years, the 28 -day mortality rate escalated to $88 \%$.

Conclusions: In our study, we identified a risk group with an exceedingly high mortality rate: the patients with an age $\geq 72$ years and presenting with hypotension (MAP $<65 \mathrm{mmHg}$ ). These data can be easily obtained at the time of the very first patient contact. As a result, an aggressive and a more effective treatment can be initiated within the first minutes of the primary care, possibly reducing organ failure and short-term mortality in this risk group.
\end{abstract}

Key words: sepsis, risk assessment, biomarkers, hemodynamics, shock 


\section{Introduction}

Septic shock is a life threatening condition associated with high rates of mortality and morbidity. Early recognition and source control as well as effective therapy including appropriate antimicrobial agents and hemodynamic stabilization are the most important cornerstones of sepsis therapy. In the last decade, early goal-directed therapy (EGDT) introduced by Rivers and coworkers became a widely accepted strategy in the initial hemodynamic resuscitation of patients in septic shock ${ }^{1}$ and gained a central position in previous and recent international guidelines ${ }^{2,3}$. But despite these advances in diagnostic and therapeutic strategies and the implementation of new approaches in the treatment of sepsis and septic shock, the prognosis still remains poor ${ }^{4}$.

Bedside assessment of reliable variables to predict the outcome of patients in the early course of septic shock would be desirable to help clinicians to provide an earlier optimal care. Currently, established severity score systems like APACHE II score or SAPS II score predict the outcome of critically ill patients on the bases of variables obtained only after the first 24 hours 5,6, whereas the early risk assessment at the point of intensive care unit (ICU) admission might be essential for the optimization of the individual therapeutic strategy, the initial hemodynamic resuscitation approach and the prediction of short-term survival.

Thus, we established a set of predictors of adverse outcome, based on hemodynamic parameters and cardiac biomarkers which can easily be obtained during primary care at ICU admission. We hypothesized that these variables might be associated with clinically relevant adverse outcome if present at ICU admission and could reliably be used to identify patients at risk for a worse short-term survival.

\section{Methods}

\section{Study Population and Definition of Septic Shock}

Between August 2009 and December 2010, 52 patients admitted with signs and symptoms of untreated septic shock, manifested within 24 hours before admission, were prospectively enrolled in this study.

Septic shock was defined according to current guidelines ${ }^{3}$ as follows: the presence of infection and the fulfillment of systemic inflammatory response syndrome. A systolic blood pressure less than 90 $\mathrm{mmHg}$ or a mean arterial blood pressure less than 65 $\mathrm{mmHg}$ respectively, persisting over a 30 -minute period despite adequate fluid resuscitation (defined as $30 \mathrm{ml}$ crystalloid-fluid per $\mathrm{kg}$ of body weight within 30 minutes) or the need of continuous administration of vasopressors. Exclusion criteria were the age $<18$ years and ARDS-patients ventilated mechanically in prone position.

Hemodynamic parameters and cardiac biomarkers at the point of admission were evaluated in regard to their prognostic ability concerning the short-term survival. The primary endpoint was all-cause mortality within 28 days after admission. The study complies with the Declaration of Helsinki; the local ethics committee approved the study.

\section{Definition of Risk Factors: Hemodynamic pa- rameters and cardiac biomarkers}

Hemodynamic variables and cardiac biomarkers were evaluated at ICU admission. Potential predictors of adverse outcome were considered as being present when meeting one of the following criteria: 1) mean arterial blood pressure (MAP) $<65 \mathrm{mmHg}$; 2) central venous pressure (CVP) $\leq 12 \mathrm{mmHg} ; 3)$ central venous oxygen saturation $\left.\left(\mathrm{ScvO}_{2}\right)<70 \% ; 4\right)$ hematocrit (HTC) $<30 \% ; 5)$ troponin I (TnI) $>0.015 \mathrm{ng} / \mathrm{ml}$ as an indicator of myocardial damage; 6) the presence of cardiac dysfunction, defined as a left ventricular ejection fraction (LVEF) $<40 \%$.

Hemodynamic assessment included continuous measurement of heart rate and continuous invasive measurement of arterial blood pressure. CVP and $\mathrm{ScvO}_{2}$ were collected at admission and repeated every 4 hours. Laboratory methods included routine parameters (including NTproBNP) as part of the primary care at ICU admission. Blood samples were drawn from arterial blood and measured immediately after blood withdrawal by standardized methods.

\section{Treatment of septic shock}

All patients received the best medical treatment according to current guidelines ${ }^{3}$ : empiric antibiotic treatment was initiated within the first three hours of recognition of sepsis. The selected anti-infective agents included activity against all likely pathogens. Microbiologic sampling was performed prior to the first antimicrobial dose, including blood cultures, lower respiratory tract sample, urine sample and, if indicated, cultures from pleural effusion or ascites. Hemodynamic resuscitation included the administration of crystalloid fluid to achieve a CVP of $\geq 8 \mathrm{mmHg}$. In case of persistent hypotension, vasopressors were applied to maintain a MAP $\geq 65 \mathrm{mmHg}$. Inotropic agents were used if $\mathrm{ScvO}_{2}$ was $<70 \%$. If mechanical ventilation was needed, all patients were sedated with propofol or midazolam and sufentanyl (Richmond Agitation-Sedation Scale -3/-4).

\section{Data Collection}

Baseline demographics, the history of cardiovascular disease, the (assumed) focus of infection, 
antibiotic treatment and Horowitz quotient $\left(\mathrm{PaO}_{2} / \mathrm{FiO}_{2}\right)$ were extracted from the patient's medical file and the hospital's electronic database at ICU admission. The Acute Physiology And Chronic Health Evaluation II Score (APACHE II) and Sepsis related Organ Failure Assessment Score (SOFA) were calculated 24 hours after admission to the ICU. The data collection included volume resuscitation and vasopressor or inotrope utilization during the first 24 hours.

\section{Echocardiography Study}

As part of the hemodynamic assessment, transthoratic echocardiography was performed in apical four and two chamber view at ICU admission (Acussion CV70, Siemens AG, Munich, Germany). LVEF was measured using the Simpson's monoplane method. Patients were classified by their LVEF into four groups (normal, mild, moderate or severe depressed) according to the American College of Cardiology/European Society of Cardiology (ACC/ESC) guidelines 7 .

\section{Statistical analysis}

Categorical variables were summarized as percentages. Continuous data was described by mean or median if skewed, range and standard deviation (SD). The Mann-Whitney test was used to compare continuous data among different patient groups. Significant association of binary variables with mortality was assessed by the Fisher's exact test, followed by a calculation of odds ratio and $95 \% \mathrm{CI}$ to compare the risk of death between the patient groups.

We constructed two logistic regression models with multivariable analysis to assess the impact of the predefined risk factors on the 28-day survival. The first model was adjusted for age, gender and history of coronary artery disease as predictor variables. Additionally we entered all defined hemodynamic risk factors with a $\mathrm{p}<0.05$ in the bivariate analysis as complementing predictor variables (called Model A). The second multivariate model was adjusted for age, gender, history of coronary artery disease and all hemodynamic variables as predictor variables (called Model B). The 28-day mortality was defined as the outcome variable. For all predictor variables included in the logistic regression model, the odds ratio and 95\% CI were calculated to assess the effect size of the risk factor on the outcome. $\mathrm{P}<0.05$ was considered statistically significant. Analyses were carried out using IBM SPSSv.19.0 (IBM Corporation, New York, United States of America).

\section{Results}

All 52 patients met the inclusion criteria of septic shock with multiple organ failure and were therefore enrolled in this study. Table 1 presents the baseline characteristics for all patients, survivors and non-survivors.

Table 1. Baseline characteristics

\begin{tabular}{|c|c|c|c|c|}
\hline & all subjects $(n=52)$ & Survivors $(\mathrm{n}=24)$ & non-survivors $(\mathrm{n}=28)$ & p-value \\
\hline Age, yr & $71.4 \pm 8.5$ & $68.4 \pm 6.9$ & $74.1 \pm 9.0$ & 0.16 \\
\hline Male, n (\%) & $31(59.6)$ & $13(41.9)$ & $18(58.1)$ & 0.64 \\
\hline \multicolumn{5}{|l|}{ Cardiac comorbidities a, $\mathrm{n}(\%)$} \\
\hline Coronary artery disease & $33(62.7)$ & $15(45.5)$ & $18(54.5)$ & 1.0 \\
\hline Atrial fibrillation & $21(39.9)$ & $10(47.6)$ & $11(52.4)$ & 1.0 \\
\hline Mitral valve prolapse & $10(19.0)$ & $5(50.0)$ & $5(50.0)$ & 1.0 \\
\hline Aortic valve stenosis & $6(11.4)$ & $3(50.0)$ & $3(50.0)$ & 1.0 \\
\hline Aortic valve regurgitation & $3(5.7)$ & $1(33.3)$ & $2(66.7)$ & 1.0 \\
\hline Dilatative cardiomyopathy & $3(5.7)$ & $1(33.3)$ & $2(66.7)$ & 1.0 \\
\hline \multicolumn{5}{|l|}{ Site of infection ${ }^{a}, \mathrm{n}(\%)$} \\
\hline Pulmonary & $36(68.4)$ & $16(44.4)$ & $20(55.6)$ & 0.76 \\
\hline Intra-abdominal & $6(11.4)$ & $2(33.3)$ & $4(66.7)$ & 0.67 \\
\hline Urosepsis & $6(11.4)$ & $3(50.0)$ & $3(50.0)$ & 1.0 \\
\hline Neurological & $1(1.9)$ & $0(0.0)$ & $1(100.0)$ & 0.46 \\
\hline unknown & $3(5.7)$ & $2(66.7)$ & $1(33.3)$ & 1.0 \\
\hline APACHE II Score & $37.0 \pm 7.6$ & $34.9 \pm 7.3$ & $38.8 \pm 7.5$ & 0.06 \\
\hline SOFA Score & $12.5 \pm 2.1$ & $11.8 \pm 1.9$ & $13.0 \pm 2.3$ & 0.03 \\
\hline Hemoglobin, g/dl & $10.5 \pm 1.9$ & $10.9 \pm 1.9$ & $10.3 \pm 1.9$ & 0.20 \\
\hline Hematocrit, \% & $31.2 \pm 5.5$ & $32.0 \pm 5.7$ & $30.8 \pm 5.5$ & 0.36 \\
\hline WBC count, /nl & $17.8 \pm 9.3$ & $16.4 \pm 6.6$ & $18.9 \pm 11.1$ & 0.32 \\
\hline Procalcitonin >2 ng/ml, n (\%) & $35(67.3)$ & $14(40.0)$ & $21(60.0)$ & 0.24 \\
\hline Creatinine, mg/dl & $2.4 \pm 1.6$ & $2.1 \pm 1.3$ & $2.7 \pm 1.8$ & 0.21 \\
\hline Bilirubin, $\mathrm{mg} / \mathrm{dl}$ & $0.8 \pm 0.8$ & $0.8 \pm 1.0$ & $0.7 \pm 0.5$ & 0.71 \\
\hline Lactat, mmol/1 & $2.6 \pm 2.9$ & $1.6 \pm 1.1$ & $3.6 \pm 3.6$ & 0.01 \\
\hline
\end{tabular}




\begin{tabular}{|c|c|c|c|c|}
\hline NTproBNP, pg/ml & $1836 \pm 23494$ & $1177 \pm 1854$ & $8623 \pm 34296$ & 0.05 \\
\hline $\mathrm{pO}_{2}, \mathrm{mmHg}$ & $81.1 \pm 25.8$ & $84.9 \pm 26.7$ & $77.9 \pm 25.1$ & 0.34 \\
\hline $\mathrm{PCO}_{2}, \mathrm{mmHg}$ & $40.2 \pm 9.9$ & $43.8 \pm 10.9$ & $37.3 \pm 8.0$ & 0.01 \\
\hline Oxygenation index $\left(\mathrm{PaO}_{2} / \mathrm{FiO}_{2}\right), \mathrm{mmHg}$ & $202.0 \pm 99.2$ & $204.6 \pm 108.4$ & $201.0 \pm 92.2$ & 0.90 \\
\hline $\mathrm{PaO}_{2} / \mathrm{FiO}_{2}<300 \mathrm{mmHg}, \mathrm{n}(\%)$ & $44(84.6)$ & $19(43.1)$ & $25(56.8)$ & 0.47 \\
\hline $\mathrm{PaO}_{2} / \mathrm{FiO}_{2}<200 \mathrm{mmHg}, \mathrm{n}(\%)$ & $28(53.8)$ & $12(42.9)$ & $16(57.1)$ & 0.10 \\
\hline Mean volume resuscitation, $\mathrm{ml}$ & $6263 \pm 2886$ & $5624 \pm 2884$ & $6811 \pm 2823$ & 0.14 \\
\hline Volume MAP $<65 \mathrm{mmHg}, \mathrm{ml}$ & $6929 \pm 3086$ & $6396 \pm 3510$ & $7116 \pm 3000$ & 0.60 \\
\hline Volume MAP $\geq 65 \mathrm{mmHg}, \mathrm{ml}$ & $5543 \pm 2518$ & $5306 \pm 2640$ & $6047 \pm 2320$ & 0.50 \\
\hline Mean dosage of Norepinephrine, $\mu \mathrm{g} / \mathrm{kg} / \mathrm{min}$ & $0.5 \pm 1.1$ & $0.6 \pm 1.4$ & $0.5 \pm 0.9$ & 0.90 \\
\hline
\end{tabular}

a clinically evaluated by the emergency physician

In accordance with the inclusion criteria of the present study, each of the enrolled patients suffered from at least one organ dysfunction: all patients suffered from circulatory failure, which is immanent in every shock. Vasopressors were used in $96 \%$ of all cases, of whom all required noradrenalin. 20 patients $(38 \%)$ received dobutamine as an additional inotropic agent, and ten patients (19\%) needed adrenalin to sustain a MAP $>65 \mathrm{mmHg}$. An increased Troponin I was found in $63 \%$ with a mean value of $3.3 \pm 10.2$ $\mathrm{ng} / \mathrm{ml} .90 \%$ of the enrolled patients received mechanical ventilation. Among these, $85 \%$ had oxygenation indices $\left(\mathrm{paO}_{2} / \mathrm{FiO}_{2}\right)$ of $<300 \mathrm{mmHg}$, while $54 \%$ showed oxygenation indices of $<200 \mathrm{mmHg}$. Furthermore, acute kidney failure occurred in $77 \%$ of all cases with a mean plasma creatinin of $2.4 \pm 1.6 \mathrm{mg} / \mathrm{dl}$ and a glomerular filtration rate (GFR) of $40 \mathrm{ml} / \mathrm{min} / 1.73 \mathrm{~m}^{2}, 38 \%$ of the patients required continuous hemofiltration. Thrombocytopenia with platelet count $<150 / \mathrm{nl}$ was present in $23 \%$. Mental disorders in order to determine a septic encephalopathy were not documented.

In spite of the study population's mean $\mathrm{pH}$ of 7.35 at the lower end of normal range as recorded at ICU admission, $63 \%$ of all cases showed an altered pH: $44 \%$ were presented with acidosis (mean $\mathrm{pH} 7.24$ ) while $17 \%$ were presented with alkalosis (mean $\mathrm{pH}$ 7.52).

\section{Mortality and hemodynamic parameters}

28 of 52 enrolled patients (54\%) died within the observation period of 28 days ("non-survivors"), and therefore meet the primary endpoint of this study. The data of hemodynamic variables at ICU admission are summarized in Table 2. With the exception of a MAP $<65 \mathrm{mmHg}$, there was no significant association between the initially reduced hemodynamic indices $\mathrm{CVP}, \mathrm{ScvO}_{2}, \mathrm{LVEF}, \mathrm{HCT}$ or elevated TnI at the time of ICU admission and 28-day mortality, all p >0.05 (Table 3).

An initial MAP $<65 \mathrm{mmHg}$ was found in 26 cases $(50 \%)$ and was classified as "hypotension present group". Those patients presented with hypotension at ICU admission, had significantly higher rates of the 28-day mortality as compared with the group of patients in which hypotension was absent (28-day mortality rate $73 \%$ vs. $27 \%, p=0.012$ ). Subjects in the group without hypotension had a longer mean survival time than patients in the hypotension present group (23.7 vs. 13.7 days, $p=0.002$ ) (Table 4 ). While all of the 26 patients within the group without hypotension survived at least 72 hours, 4 of the 26 patients with hypotension died within the first 24 hours.

Table 2. Hemodynamic variables

\begin{tabular}{lllll}
\hline & $\begin{array}{l}\text { all subjects } \\
(\mathrm{n}=52)\end{array}$ & $\begin{array}{l}\text { survivors } \\
(\mathrm{n}=24)\end{array}$ & $\begin{array}{l}\text { non-survivors } \\
(\mathrm{n}=28)\end{array}$ & p-value \\
\hline $\mathrm{MAP}, \mathrm{mmHg}$ & $64.7 \pm 14.7$ & $71.9 \pm 12.7$ & $63.3 \pm 15.4$ & 0.012 \\
$\mathrm{ScvO}_{2}, \%$ & $65.5 \pm 11.2$ & $63.7 \pm 11.1$ & $67.3 \pm 11.4$ & 0.51 \\
$\mathrm{CVP}, \mathrm{mmHg}$ & $9.5 \pm 4.5$ & $10.2 \pm 4.9$ & $9.0 \pm 4.1$ & 0.46 \\
$\mathrm{LVEF}, \%(\mathrm{n}=45)$ & $43.6 \pm 13.5$ & $46.1 \pm 13.1$ & $41.6 \pm 13.1$ & 0.45 \\
$\mathrm{TnI}, \mathrm{ng} / \mathrm{ml}$ & $3.3 \pm 10.3$ & $4.5 \pm 11.3$ & $2.5 \pm 9.5$ & 0.78 \\
$\mathrm{Hct}, \%$ & $31.2 \pm 5.5$ & $30.5 \pm 5.4$ & $32.0 \pm 5.6$ & 0.66 \\
\hline
\end{tabular}

Table 3. Hemodynamic function and outcome

\begin{tabular}{|c|c|c|c|c|}
\hline & $\mathrm{n}$ & $\begin{array}{l}\text { survivors, } \\
\mathrm{n}(\%)\end{array}$ & $\begin{array}{l}\text { non-survivors, } \\
\mathrm{n}(\%)\end{array}$ & OR $(95 \%-C I), p$-value \\
\hline \multicolumn{5}{|c|}{$\mathrm{MAP}, \mathrm{mmHg}$} \\
\hline$\geq 65$ & 26 & $17(65.4)$ & $9(34.6)$ & \\
\hline$<65$ & 26 & $7(26.9)$ & $19(73.1)$ & $5.1(1.4-18.8), p=0.012$ \\
\hline \multicolumn{5}{|c|}{$\mathrm{ScvO}_{2}, \%$} \\
\hline$\geq 70$ & 17 & $7(41.2)$ & $10(58.8)$ & \\
\hline$<70$ & 31 & $16(51.6)$ & $15(48.4)$ & $0.7(0.2-2.2), p=0.556$ \\
\hline \multicolumn{5}{|c|}{$\mathrm{CVP}, \mathrm{mmHg}$} \\
\hline$>12$ & 13 & $7(53.8)$ & $6(46.2)$ & \\
\hline$\leq 12$ & 36 & $15(41.7)$ & $21(58.3)$ & $1.6(0.4-6.0), p=0.525$ \\
\hline \multicolumn{5}{|l|}{ НCТ, \% } \\
\hline$\geq 30$ & 29 & $14(48.3)$ & $15(51.7)$ & \\
\hline$<30$ & 23 & $10(43.5)$ & $13(56.5)$ & $1.2(0.4-3.7), p=0.785$ \\
\hline \multicolumn{5}{|c|}{ TnI, ng/ml } \\
\hline$\leq 0.015$ & 15 & $8(53.3)$ & $7(46.7)$ & \\
\hline$>0.015$ & 33 & $13(39.4)$ & $20(60.6)$ & $1.8(0.5-6.2), p=0.531$ \\
\hline \multicolumn{5}{|c|}{ LVEF, \% } \\
\hline$\geq 40$ & 28 & $14(50.0)$ & $14(50.0)$ & \\
\hline$<40$ & 17 & $6(35.3)$ & $11(64.7)$ & $1.7(0.5-6.0), \mathrm{p}=0.534$ \\
\hline
\end{tabular}

The patients in the hypotension present group had significantly higher lactate concentration $(p=0.002)$, higher serum creatinin $(p=0.04)$, higher NTproBNP $(p=0.03)$ and after the first 24 hours higher APACHE II scores $(p=0.04)$ (Table 4). 
Table 4. Organ function and survival time of survivors and non-survivors from hypotension group

\begin{tabular}{|c|c|c|c|c|c|}
\hline & \multicolumn{3}{|c|}{ MAP $<65$ mmHg $(n=26)$} & \multirow{2}{*}{$\begin{array}{l}\mathrm{MAP} \geq 65 \mathrm{mmHg} \\
(\mathrm{n}=26)\end{array}$} & \multirow[t]{2}{*}{ p-value a } \\
\hline & all subjects & Survivors & Non-survivors & & \\
\hline Age, yr & $73.3 \pm 9.3$ & $67.4 \pm 7.1$ & $75.0 \pm 9.3$ & $69.6 \pm 7.4$ & 0.12 \\
\hline Male, n (\%) & $18(69.2)$ & $4(15.3)$ & $14(53.8)$ & $13(50.0)$ & 0.39 \\
\hline \multicolumn{6}{|l|}{ Cardiac comorbidities a, n (\%) } \\
\hline Coronary artery disease & $17(65.3)$ & $4(15.3)$ & $13(50.0)$ & $16(61.5)$ & 1.0 \\
\hline Atrial fibrillation & $11(42.3)$ & $3(11.5)$ & $8(30.7)$ & $10(38.5)$ & 1.0 \\
\hline Mitral valve prolapse & $5(19.2)$ & $1(10.0)$ & $4(15.3)$ & $5(19.2)$ & 1.0 \\
\hline Aortic valve stenosis & $3(11.5)$ & 0 & $3(11.5)$ & $3(11.5)$ & 1.0 \\
\hline Aortic valve regurgitation & $2(7.7)$ & $1(3.8)$ & $1(3.8)$ & $1(3.8)$ & 1.0 \\
\hline Dilatative cardiomyopathy & $2(7.7)$ & 0 & $2(7.7)$ & $1(3.8)$ & 1.0 \\
\hline \multicolumn{6}{|l|}{ Site of infection a, $\mathrm{n}(\%)$} \\
\hline Pulmonary & $19(73.0)$ & $8(30.7)$ & $11(42.3)$ & $17(65.3)$ & 1.0 \\
\hline Intra-abdominal & $3(11.5)$ & 0 & $3(11.5)$ & $3(11.5)$ & 1.0 \\
\hline Urosepsis & $3(11.5)$ & $1(3.8)$ & $2(7.7)$ & $3(11.5)$ & 1.0 \\
\hline Neurological & $1(3.8)$ & 0 & $1(3.8)$ & 0 & 0.46 \\
\hline unknown & $1(3.8)$ & 0 & $1(3.8)$ & $2(7.7)$ & 1.0 \\
\hline APACHE II Score & $39.0 \pm 8.2$ & $36.6 \pm 10.0$ & $40.0 \pm 7.6$ & $34.7 \pm 6.3$ & 0.04 \\
\hline SOFA Score & $12.8 \pm 2.2$ & $12.7 \pm 1.6$ & $12.8 \pm 2.4$ & $12.2 \pm 2.1$ & 0.31 \\
\hline Hemoglobin, g/dl & $9.8 \pm 1.4$ & $10.5 \pm 1.5$ & $9.6 \pm 1.4$ & $11.4 \pm 1.9$ & $<0.01$ \\
\hline Hematocrit, \% & $29.4 \pm 4.3$ & $30.9 \pm 4.3$ & $28.9 \pm 4.4$ & $33.1 \pm 6.1$ & 0.01 \\
\hline WBC count, /nl & $19.5 \pm 10.4$ & $17.7 \pm 3.9$ & $20.1 \pm 11.9$ & $15.9 \pm 7.8$ & 0.17 \\
\hline Procalcitonin >2 ng/ml, n (\%) & $21(60.0)$ & $6(17.1)$ & $15(42.9)$ & $14(40.0)$ & 0.14 \\
\hline Creatinine, mg/dl & $2.8 \pm 1.8$ & $2.5 \pm 1.8$ & $2.9 \pm 1.9$ & $1.9 \pm 1.1$ & 0.04 \\
\hline Bilirubin, mg/dl & $0.8 \pm 1.0$ & $0.6 \pm 0.3$ & $0.8 \pm 0.5$ & $0.7 \pm 0.5$ & 0.71 \\
\hline Lactat, mmol/1 & $3.7 \pm 3.7$ & $2.1 \pm 1.2$ & $4.2 \pm 4.1$ & $1.5 \pm 0.9$ & $<0.01$ \\
\hline NTproBNP, pg/ml & $4136 \pm 33619$ & $9634 \pm 41936$ & $1086 \pm 2783$ & $1341 \pm 4966$ & 0.03 \\
\hline $\mathrm{pO}_{2}, \mathrm{mmHg}$ & $76.5 \pm 25.5$ & $88.3 \pm 31$ & $72.7 \pm 22.4$ & $86.2 \pm 25.6$ & 0.17 \\
\hline $\mathrm{PCO}_{2}, \mathrm{mmHg}$ & $40.8 \pm 10.3$ & $45.2 \pm 13.3$ & $37.9 \pm 7.7$ & $39.8 \pm 9.7$ & 0.70 \\
\hline Oxygenation index $\left(\mathrm{PaO}_{2} / \mathrm{FiO}_{2}\right), \mathrm{mmHg}$ & $202.6 \pm 111.7$ & $207.6 \pm 147.0$ & $200.8 \pm 101.1$ & $203.3 \pm 85$ & 0.97 \\
\hline $\mathrm{PaO}_{2} / \mathrm{FiO}_{2}<300 \mathrm{mmHg}, \mathrm{n}(\%)$ & $24(92.3)$ & $8(30.7)$ & $16(61.5)$ & $20(76.9)$ & 0.45 \\
\hline $\mathrm{PaO}_{2} / \mathrm{FiO}_{2}<200$ mmHg, n (\%) & $14(53.8)$ & $5(19.2)$ & $9(34.6)$ & $14(53.8)$ & 0.78 \\
\hline Mean volume resuscitation, $\mathrm{ml}$ & $6929 \pm 3086$ & $6396 \pm 3510$ & $7116 \pm 3000$ & $5543 \pm 2518$ & 0.08 \\
\hline Dosage of Norepinephrine, $\mu \mathrm{g} / \mathrm{kg} / \mathrm{min}$ & $0.5 \pm 0.9$ & $0.3 \pm 0.3$ & $0.6 \pm 1.0$ & $0.6 \pm 1.4$ & 0.90 \\
\hline Mean survival, days & $13.7 \pm 10.4$ & $28.0 \pm 0$ & $9.2 \pm 6.7$ & $23.7 \pm 8.9$ & 0.002 \\
\hline 28-day-mortality, \% & 73 & & & 27 & 0.001 \\
\hline
\end{tabular}

a $\mathrm{p}$-value for comparison of variables between patients with $\mathrm{MAP}<65 \mathrm{mmHg}$ and $\mathrm{MAP} \geq 65 \mathrm{mmHg}$

As a result of the study population's mean age of $71.4 \pm 8.5$ years, we defined 72 years as a cut-off value for the variable age. If hypotension coincided with an age $\geq 72$ years ( 15 patients or $29 \%$ of the study group), the 28-day mortality rate was markedly increased up to $88 \%$ (Table 5). We therefore defined the age $\geq 72$ years post-hoc as a predictor of adverse outcome and it was entered in the logistic regression model as we strongly expected it to influence the 28-day mortality.

Table 5. Survival rates for MAP $<65 \mathrm{mmHg}$ and age $>72$ years

\begin{tabular}{llll}
\hline & survivors & \\
\hline Age, MAP & Yes & No & Total \\
$<72$ years, $>65 \mathrm{mmHg}$ & 12 & 5 & 17 \\
& $70.6 \%$ & $29.4 \%$ & $100.0 \%$ \\
$<72$ years, $\leq 65 \mathrm{mmHg}$ & 5 & 4 & 9 \\
& $55.6 \%$ & $44.4 \%$ & $100.0 \%$ \\
$\geq 72$ years, $>65 \mathrm{mmHg}$ & 5 & 4 & 9 \\
& $55.6 \%$ & $44.4 \%$ & $100.0 \%$ \\
& 2 & 15 & 17 \\
Total & $11.8 \%$ & $88.2 \%$ & $100.0 \%$ \\
& 24 & 28 & 52 \\
& $46.1 \%$ & $53.9 \%$ & $100.0 \%$
\end{tabular}

In the first multivariate regression analysis (Model A, Table 6), the variables age $\geq 72$ years $(p=0.01)$ and MAP $<65 \mathrm{mmHg}(\mathrm{p}=0.008)$ were significantly associated with an increased mortality rate. The odds of mortality was 4.1 (95\% CI, 1.1 - 14.8) higher for the hypotension present group compared to the group without hypotension. The impact of an age $\geq 72$ years significantly increases the odds of dying to $4.0(95 \% \mathrm{CI}, 1.0-15.0)$. These results indicate a four-fold increase in the risk of death for both factors. The logistic regression model is therefore consistent with the results of the bivariate analysis performed earlier. Finally, the results of the second logistic regression (Model B, Table 6) are in line with the bivariate and multivariate analysis presented above.

\section{Vasopressors and inotropic agents}

$96 \%$ of the patients needed vasopressor and/or inotrope agents during the first 24 hours to sustain a MAP $>65 \mathrm{mmHg}$ despite crystalloid fluid challenge. In the univariate analysis, there was no significant difference in the volume application or the vasopres- 
sor/inotropic dosage between the survivors and non-survivors within the first 24 hours, all $p=<0.05$.

Though 31 patients $(65 \%)$ were presented with $\mathrm{ScvO}_{2}$ levels $<70 \%$, only 20 patients $(39 \%)$ were treated with dobutamine. Furthermore, 6 patients $(12 \%)$ who received dobutamine showed $\mathrm{ScvO}_{2}$ values of $>70 \%$. Table 7 illustrates the hemodynamic of patients treated with dobutamine versus patients who did not receive dobutamine.

\section{Transthoratic echocardiography}

Transthoratic echocardiography could be obtained in 45 cases (86\%). The quantitative evaluation of LVEF was classified according to the ACC/ESC guidelines ${ }^{7}$, results are shown in Table 8.

\section{Missing data}

Among all included patients, there was an incomplete data set in 10 cases $(19 \%)$. As indicated in Table 8, echocardiography could not be performed in 7 cases (14\%). Furthermore, we had missing data in connection to 3 other patients $(6 \%)$, which affected $\mathrm{CVP}$ and $\mathrm{ScvO}_{2}$ due to a missing central catheter at the time of examination. TnI was not obtained in 4 cases $(8 \%)$.

Table 6. Multivariate logistic regression: Model A and Model B

\begin{tabular}{lllll}
\hline & \multicolumn{2}{c}{ Model A $(\mathrm{n}=52)$} & \multicolumn{2}{c}{ Model B $(\mathrm{n}=42)$} \\
\hline Variable & OR $(95 \%-\mathrm{CI})$ & $\mathrm{p}$-value & OR $(95 \%-\mathrm{CI})$ & $\mathrm{p}$-value \\
\hline Men & $2.3(0.6-8.9)$ & 0.23 & $2.0(0.4-8.6)$ & 0.37 \\
Age $\geq 72$ years & $4.0(1.0-15.0)$ & 0.01 & $9.8(1.4-68.2)$ & 0.02 \\
CAD & $0.6(0.1-3.4)$ & 0.59 & $0.6(0.1-2.9)$ & 0.56 \\
MAP $\leq 65 \mathrm{mmHg}$ & $4.1(1.1-14.8)$ & 0.008 & $18.8(2.4-148.2)$ & 0.005 \\
CVP $\leq 12 \mathrm{mmHg}$ & - & - & $1.8(0.3-10.4)$ & 0.48 \\
$\mathrm{ScvO} 2 \leq 70 \%$ & - & - & $0.4(0.1-2.5)$ & 0.04 \\
$\mathrm{HTC}<30 \%$ & - & - & $0.6(0.1-3.7)$ & 0.47 \\
TnI $\geq 0.15 \mathrm{ng} / \mathrm{ml}$ & - & - & $1.0(0.9-1.0)$ & 0.98 \\
LVEF $<40 \%$ & - & - & $0.8(0.1-4.7)$ & 0.85 \\
\hline
\end{tabular}

Table 7. Hemodynamic function of patients with dobutamine vs. without dobutamine

\begin{tabular}{llll}
\hline & $\begin{array}{l}\text { With dobuta- } \\
\text { mine }(\mathrm{n}=20)\end{array}$ & $\begin{array}{l}\text { Without dobuta- } \\
\text { mine }(\mathrm{n}=32)\end{array}$ & p-value \\
\hline $\mathrm{MAP}, \mathrm{mmHg}$ & $63.0 \pm 14.9$ & $69.9 \pm 9.0$ & 0.10 \\
$\mathrm{NTproBNP}, \mathrm{pg} / \mathrm{ml}$ & $17285 \pm 40808$ & $4133 \pm 6848$ & 0.10 \\
Lactate, $\mathrm{mmol} / \mathrm{1}$ & $3.9 \pm 3.7$ & $1.8 \pm 2.0$ & 0.01 \\
$\mathrm{TnI}, \mathrm{ng} / \mathrm{ml}$ & $6.0 \pm 15.0$ & $1.5 \pm 3.1$ & 0.13 \\
$\mathrm{ScvO}_{2}, \%$ & $64.1 \pm 14.3$ & $66.6 \pm 14.9$ & 0.45 \\
$\mathrm{LVEF}, \%$ & $38.5 \pm 15.2$ & $47.4 \pm 10.9$ & 0.02 \\
$\begin{array}{l}\text { Mean norepinephrine } \\
\text { dosage, } \mu \mathrm{g} / \mathrm{kg} / \mathrm{min}\end{array}$ & $1.0 \pm 1.7$ & $0.2 \pm 0.2$ & 0.01 \\
\hline
\end{tabular}

\section{Discussion}

Well established tools for risk stratification and prediction of death of critically ill patients are the APACHE II and SOFA score. Both of them can tech- nically be only evaluated after 24 hours and not obtained at ICU admission. It has been previously documented that the improvement of hemodynamic function leads to the highest benefit of survival and a delayed treatment of cardiovascular organ failure is associated with an increased mortality ${ }^{8}$. Therefore, our idea was the earliest possible risk assessment in patients with septic shock - which in the present study is at ICU admission - using hemodynamic parameters and cardiac biomarkers.

Table 8. Echocardiography

\begin{tabular}{|c|c|c|c|c|}
\hline & $\begin{array}{l}\text { all subjects } \\
(\mathrm{n}=52)\end{array}$ & $\begin{array}{l}\text { survivors } \\
(\mathrm{n}=24)\end{array}$ & $\begin{array}{l}\text { non-survivors } \\
(\mathrm{n}=28)\end{array}$ & p-value \\
\hline Mean LVEF, (\%) & $43.6 \pm 13.5$ & $46.1 \pm 13.1$ & $41.6 \pm 13.7$ & 0.26 \\
\hline $\begin{array}{l}\text { Normal LVEF }(\geq 55 \%), n \\
(\%)\end{array}$ & $17(32.6)$ & $9(17.2)$ & $8(15.4)$ & 0.56 \\
\hline $\begin{array}{l}\text { Mildly depressed LVEF } \\
(45-54 \%), \mathrm{n}(\%)\end{array}$ & $2(3.8)$ & $1(1.9)$ & $1(1.9)$ & 1.0 \\
\hline $\begin{array}{l}\text { Moderately depressed } \\
\text { LVEF }(30-44 \%), \mathrm{n}(\%)\end{array}$ & $18(34.6)$ & $7(13.5)$ & $11(21.1)$ & 0.76 \\
\hline $\begin{array}{l}\text { Severely depressed LVEF } \\
(<30 \%), \mathrm{n}(\%)\end{array}$ & $8(15.4)$ & $3(5.8)$ & $5(9.6)$ & 0.97 \\
\hline $\begin{array}{l}\text { No echocardiography } \\
\text { possible, } \mathrm{n}(\%)\end{array}$ & $7(13.5)$ & $4(7.7)$ & $3(5.8)$ & 0.29 \\
\hline
\end{tabular}

The key findings of the present study are as follows: a mean arterial blood pressure of $<65 \mathrm{mmHg}$ at the time of ICU admission was the only hemodynamic factor associated with an increased rate of the 28-day mortality. A decreased CVP was of no prognostic value regarding the 28-day survival in this study, nor was a decreased $\mathrm{ScvO}_{2}$ or hematocrit, an increased troponin I or altered LVEF.

Our results support the findings of previous studies in which hypotension is clearly associated with adverse outcome in critically ill patients ${ }^{9-12}$. A MAP $<65 \mathrm{mmHg}$ might therefore be suitable as a prognostic factor at ICU admission for patients presented in septic shock. This is particularly the case with regard to elderly patients with an age $\geq 72$ years. Here we demonstrated a 28 -day mortality rate of $88 \%$.

The patients in the group with hypotension had an increased risk of death in all three performed statistical analyses - the bivariate analysis and both logistic regression models. As a result of missing data described in the results section, 10 patients could not be included into the second multivariate regression model (Model B), which therefore only consisted of 42 patients. Due to this smaller sample size, statistics from this particular analysis seem to be more inaccurate, indicated by an OR $(95 \%-\mathrm{CI})$ of $18.8(2.4-148.2)$ for the variable MAP $<65 \mathrm{mmHg}$. Still, in particular the bivariate analysis and the first logistic regression model (Model A: variables age, gender, known CAD and MAP $<65 \mathrm{mmHg}$ ) indicated a four-fold increased risk of death if hypotension is present. Not surpris- 
ingly, patients with hypotension had significantly higher degrees of organ dysfunction.

The interpretation of hemodynamic variables is a well established tool to guide intensive care therapy. Therefore, the recommended resuscitation approach for patients with septic shock suggests the use of $\mathrm{MAP}, \mathrm{CVP}, \mathrm{ScvO}_{2}$ and $\mathrm{HTC}{ }^{3}$. As the present study was unable to show an association between the impaired hemodynamic variables (other than MAP) and mortality, one has to ask for the reasons why there was no difference regarding the outcome.

Our hypothesis is that the present results differ due to the heterogeneous characteristics of our study setting as well as of our study population when compared with other studies investigating the hemodynamic resuscitation in septic shock.

\section{$\mathrm{ScrO}_{2}$}

One distinct example underlining our assumption is the following interpretation of $\mathrm{ScvO}_{2}$ and its impact on mortality, if viewed in the light of other studies:

It is known that four factors negatively influence the $\mathrm{ScvO}_{2}$ level: anemia, decreased arterial oxygen saturation, increased oxygen demand and impaired cardiac output. Mechanical ventilation on the other hand achieves an improvement of $\mathrm{ScvO}_{2}$ by optimizing oxygen balance through increased oxygen delivery $\left(\mathrm{DO}_{2}\right)$ and decreased oxygen demand $\left(\mathrm{VO}_{2}\right)$. Therefore, low pre-intubation levels of $\mathrm{ScvO}_{2}$ may rise as an effect of mechanical ventilation itself ${ }^{13}$. Rivers and colleagues described a mean $\mathrm{ScvO}_{2}$ of $49.2 \%$ at baseline for the standard therapy group and a mean $\mathrm{ScvO}_{2}$ of $48.6 \%$ for the EGDT group. The rate for mechanical ventilation was $53 \%$ within the study population ${ }^{1}$. In contrast, the mean $\mathrm{ScvO}_{2}$ level of the present study at ICU admission was mounting $65.5 \%$ with simultaneously exceedingly high mechanical ventilation rate of $90 \%$. Therefore, according to our observations an improved $\mathrm{ScvO}_{2}$ depends heavily on study setting and applied therapies.

This is in line with findings from other studies in which hemodynamic resuscitation using $\mathrm{ScvO}_{2}$ as a marker of hemodynamic function and systemic oxygenation resulted in contrary data regarding the outcome ${ }^{14-18}$. As a consequence, there has been rising concern assuming that it was premature to recommend a general applicability of resuscitation strategies in current guidelines using $\mathrm{ScvO}_{2}$ with such emphasis as a hemodynamic goal based only on data from one single-centre study 19,20.

As our data show, despite trying to follow the current guidelines in this matter, our clinical experience suggests a certain inconsistent usage of dobutamine if guided by $\mathrm{ScvO}_{2}$ levels. Only two thirds of all patients with a $\mathrm{ScvO}_{2}<70 \%$ received dobutamine while as a contrast, 6 patients were treated with inotropic agents although showing $\mathrm{ScvO}_{2}$ levels of $70 \%$ or more. As Table 7 indicates, patients who received dobutamine showed to have increased lactate levels, a decreased LVEF and a higher mean value of norepinephrine. All three might indicate a clinically more severe septic shock. As a conclusion, $\mathrm{ScvO}_{2}$ levels did not always reflect the severity of disease adequately and therapeutic concepts in these cases resulted from decisions based rather on practical experience than on guidelines. The seemingly inconsistent handling of dobutamine may raise the question whether this is partly due to the above mentioned controversy in the literature concerning a $\mathrm{ScvO}_{2}$ guided resuscitation approach.

\section{CVP}

The same holds true for CVP. Its measurement in critically ill patients is widely debated in literature, and reports of its reliability in reflecting adequate fluid status have been inconclusive ${ }^{21,22}$. Though CVP is traditionally considered to be a measure of cardiac preload, our belief was that accuracy of CVP is limited due to the different daily clinical setting of an ICU. Physicians are confronted with unselected patient groups, faced with such influences on CVP as positive pressure ventilation, elevated abdominal pressure or valve diseases combined with the patients' critical conditions.

\section{Tnl and LVEF}

Beyond the common resuscitation approach using MAP, CVP, $\mathrm{ScvO}_{2}$ and HTC, the current study investigated additional variables in the management of hemodynamic resuscitation: TnI and LVEF. TnI was measured as an indicator of myocardial damage. Several authors reported a relationship between elevated TnI levels and a worse prognosis of survival, higher severity of disease, higher incidence of organ dysfunction and a longer ICU stay 23,24 . Our included patients had elevated TnI levels in $65 \%$ of all cases and a CAD occurrence of $64 \%$ as a known comorbidity. Data from other studies differ, with an elevated TnI ranging from $15 \%$ to $85 \%$ and rates of around $20 \%$ for a known CAD.

We were not able to show a higher risk for death in patients with septic shock if TnI was increased. We hypothesize, that elevated TnI levels are more frequent in our study population due to a higher extend of preexisting CAD, leading to a higher incidence of troponin release $(73 \%$ with CAD vs. $47 \%$ without CAD).

As a second additional variable, LVEF was measured to assess the presence of a cardiac dysfunc- 
tion. The results from our study show that a reduced LVEF $<40 \%$ is a common condition in patients with septic shock, without having an impact on survival $(p=0.06)$. Indeed, these findings are in line with numerous studies, but interestingly with ambigious findings regarding their impact on survival ${ }^{25-28}$. The reasons for that might lie in physiological preconditions, as LVEF is influenced not only by contractility, but also by pre- and afterload. According to the Frank-Starling law of the heart, preload is a major determinant of cardiac output and depends on intravascular volume and venous return. If a reduced LVEF is present at the time of ICU admission, it cannot be definitely said, whether LVEF is depressed as a result of hypovolemia in the early course of septic shock or as a result of the septic cardiomyopathy itself.

We therefore assume that the LVEF alone does not sufficiently characterize the hemodynamic function in the early phase of sepsis treatment. A risk stratification regarding the outcome by using LVEF as an indicator of cardiac dysfunction does not seem feasible at this early point of assessment.

Therefore, taking all these parameter into account, another important result of our study is the observation that there are probably many factors that influence the evaluation of hemodynamic function and its impact on mortality.

\section{Baseline data of the study population}

In our study, we furthermore analyzed the baseline data of our study population and observed yield two important findings: firstly, a rather elderly study population (mean age $71.4 \pm 8.5$ years), with $80 \%$ being older than 65 years, and secondly, a relatively high APACHE II score, with a mean of $37.0 \pm 7.6$ points.

Both findings can be explained by the study setting: as a result of studying a population treated in a tertiary centre focusing on internal medicine in a well-developed country, we assume that the study collective is likely to be affected by multimorbidity and advanced age. Moreover, we would like to emphasize that without exception all of our enrolled patients suffered from septic shock with multi-organ failure. In contrast, many studies of the past included patients with sepsis as well as severe sepsis or septic shock ${ }^{4,29}$. Therefore, our inclusion criteria led to a study population with more severe diseases, reflected in a higher APACHE II score in comparison to other studies.

Additionally, socioeconomic aspects may also have contributed to a different age distribution. By comparison, as shown in the PROGRESS registry, the mean age of the patients included from Malaysia was 50.1 years. Similar age numbers can be found for other so-called newly industrialized countries such as Brazil or India ${ }^{30,31}$. In contrast, German patients showed to have a mean age of 64.2 years ${ }^{31}$.

In conclusion, the results of the current and of the past studies suggest ambiguous results regarding the outcome which are heavily depending on study settings and study populations as much as applied therapies and surrounding conditions. These respective surrounding conditions must be taken into consideration when it comes to the interpretation of results.

\section{Limitations of the present study}

We acknowledge some limitations of our study. Firstly and most importantly, due to the small number of patients enrolled and the strict focus on hemodynamic function there might also be other unconsidered factors influencing the observed mortality rate.

Finally, as a single-centre observational trial with clinical orientation, its non-experimental study design was not intended to prove causality of observed findings and their impact on the outcome. Furthermore, the results from one single-centre might not be equivalent to experiences of other medical centers.

\section{Conclusions}

The aim of the present study was the identification of risk patients at the time of ICU arrival by bedside assessment of hemodynamic function and cardiac biomarkers in septic shock. We hypothesized that once a person is being identified as a critically ill patient with a greater risk of death, it would allow the medical team to initiate a more aggressive and a more effective treatment within the first minutes of the primary care. The goal would be to achieve a quicker decision process during intensive medical care, e.g. the earlier administration of fluids, antibiotic or vasoactive agents, which can be done in any medical environment (emergency room, ICU or ward).

We demonstrated convincingly that a decreased MAP $<65 \mathrm{mmHg}$ was the only hemodynamic risk factor associated with an increased 28-day mortality rate. Although the use of echocardiography and measurement of $\mathrm{TnI}$ as variables predicting a short-term outcome showed no significant impact on survival in this trial, we assume that both parameters are a useful additional tool to assess cardiac performance during the course of septic shock if measured regularly. Multiple studies proved the benefit of an advanced hemodynamic assessment and it is evident that MAP alone cannot reflect the patient's hemodynamic function during shock in total.

The authors would like to point out that our study shows very interesting results regarding the bedside assessment in the first few hours of septic 
shock. This study was able to identify a risk group with an exceedingly high mortality rate: the patients with an age of 72 years or older, admitted to an ICU with yet untreated septic shock and presented with hypotension (MAP $<65 \mathrm{mmHg}$ ). This patient group had a 28 -day mortality rate of $88 \%$.

The importance of this finding lies in its simplicity. Organ failure and the outcome are likely to be favorably influenced by the immediate therapy and management of the case if rapidly initiated after recognition of primary objectives in the treatment. Optimal therapeutic approaches therefore include a MAP $>65 \mathrm{mmHg}$ as a target goal in the hemodynamic resuscitation. This can be assessed easily in every medical center and it is one of the first parameters which can be obtained at the time of the very first patient contact independent from medical environment.

\section{Abbreviations}

MAP: mean arterial blood pressure; CVP: central venous pressure; $\mathrm{S}_{\mathrm{cvO}}$ : central venous oxygen saturation; LVEF: left ventricular ejection fraction; HTC: Hematocrit; TnI: Troponin I; NTproBNP: N-terminal pro-brain natriuretic peptide; EGDT: early goal-directed therapy; APACHE II score: Acute Physiology And Chronic Health Evaluation II score; SAPS II score: Simplified Acute Physiology II score; SOFA score: Sepsis Related Organ Failure Assessment score; ICU: intensive care unit; ARDS: acute respiratory distress syndrome; $\mathrm{DO} 2$ : oxygen delivery; $\mathrm{VO}_{2}$ : oxygen demand; $\mathrm{FiO}_{2}$ : fraction of inspired oxygen; $\mathrm{paO}_{2}$ : arterial oxygen partial pressure

\section{Competing Interests}

The authors have declared that no competing interest exists.

\section{References}

1. Rivers E, Nguyen B, Havstad S, et al. Early goal-directed therapy in the treatment of severe sepsis and septic shock. N Engl J Med. 2001; 345: 1368-77.

2. Dellinger RP, Levy MM, Carlet JM, et al. Surviving Sepsis Campaign. international guidelines for management of severe sepsis and septic shock: 2008. Crit Care Med. 2008; 36: 296-327.

3. Dellinger RP, Levy MM, Rhodes A, et al. Surviving Sepsis Campaign. International Guidelines for Management of Severe Sepsis and Septic Shock: 2012. Crit Care Med. 2013; 41: 580-637.

4. Engel C, Brunkhorst FM, Bone HG, et al. Epidemiology of sepsis in Germany. results from a national prospective multicenter study. Intensive Care Med. 2007; 33: 606-18.

5. Knaus WA, Draper EA, Wagner DP, et al. APACHE II. a severity of disease classification system. Crit Care Med. 1985; 13: 818-29.

6. Le Gall, J R, Lemeshow S, Saulnier F. A new Simplified Acute Physiology Score (SAPS II) based on a European/North American multicenter study. JAMA. 1993; 270: 2957-63.

7. Lang RM, Bierig M, Devereux RB, et al. Recommendations for chamber quantification. a report from the American Society of Echocardiography's Guidelines and Standards Committee and the Chamber Quantification Writing Group, developed in conjunction with the European Association of Echocardiography, a branch of the European Society of Cardiology. J Am Soc Echocardiogr. 2005; 18: 1440-63.

8. Levy MM, Macias WL, Vincent JL, et al. Early changes in organ function predict eventual survival in severe sepsis. Crit Care Med. 2005; 33: 2194-201.
9. Jones AE, Yiannibas V, Johnson C, et al. Emergency department hypotension predicts sudden unexpected in-hospital mortality. a prospective cohort study. Chest. 2006; 130: 941-6.

10. Lee KL, Woodlief LH, Topol EJ, et al. Predictors of 30-day mortality in the era of reperfusion for acute myocardial infarction. Results from an international trial of 41,021 patients. GUSTO-I Investigators. Circulation. 1995; 91: 1659-68.

11. Varpula M, Tallgren $M$, Saukkonen $K$, et al. Hemodynamic variables related to outcome in septic shock. Intensive Care Med. 2005; 31: 1066-71.

12. Marchick MR, Kline JA, Jones AE. The significance of non-sustained hypotension in emergency department patients with sepsis. Intensive Care Med. 2009; 35: $1261-4$.

13. Hernandez G, Pena H, Cornejo R, et al. Impact of emergency intubation on central venous oxygen saturation in critically ill patients. a multicenter observational study. Crit Care. 2009; 13: R63.

14. Pope JV, Jones AE, Gaieski DF, et al. Multicenter study of central venous oxygen saturation $(\mathrm{ScvO}(2))$ as a predictor of mortality in patients with sepsis. Ann Emerg Med. 2010; 55: 40-46 e1.

15. Lin SM, Huang CD, Lin HC, et al. A modified goal-directed protocol improves clinical outcomes in intensive care unit patients with septic shock. a randomized controlled trial. Shock. 2006; 26: 551-7.

16. Gattinoni L, Brazzi L, Pelosi P, et al. A trial of goal-oriented hemodynamic therapy in critically ill patients. SvO2 Collaborative Group. N Engl J Med. 1995; 333: 1025-32.

17. Nguyen HB, Corbett SW, Steele R, et al. Implementation of a bundle of quality indicators for the early management of severe sepsis and septic shock is associated with decreased mortality. Crit Care Med. 2007; 35: 1105-12.

18. van Beest PA, Hofstra JJ, Schultz MJ, et al. The incidence of low venous oxygen saturation on admission to the intensive care unit. a multi-center observational study in The Netherlands. Crit Care. 2008; 12: R33.

19. Bellomo R, Reade MC, Warrillow SJ. The pursuit of a high central venous oxygen saturation in sepsis. growing concerns. Crit Care. 2008; 12: 130

20. Perel A. Bench-to-bedside review. the initial hemodynamic resuscitation of the septic patient according to Surviving Sepsis Campaign guidelines--does one size fit all? Crit Care. 2008; 12: 223.

21. Magder S. More respect for the CVP. Intensive Care Med. 1998; 24: 651-3.

22. Michard F, Teboul JL. Predicting fluid responsiveness in ICU patients. a critical analysis of the evidence. Chest. 2002; 121: 2000-8.

23. King DA, Codish S, Novack V, et al. The role of cardiac troponin I as a prognosticator in critically ill medical patients: a prospective observational cohort study. Critical care (London, England). 2005; 9: R390-5.

24. Lim W, Holinski P, Devereaux PJ, et al. Detecting myocardial infarction in critical illness using screening troponin measurements and ECG recordings. Critical care (London, England). 2008; 12: R36.

25. Poelaert J, Declerck C, Vogelaers D, et al. Left ventricular systolic and diastolic function in septic shock. Intensive Care Med. 1997; 23: 553-60.

26. Jardin F, Fourme T, Page B, et al. Persistent preload defect in severe sepsis despite fluid loading. A longitudinal echocardiographic study in patients with septic shock. Chest. 1999; 116: 1354-9.

27. Charpentier J, Luyt CE, Fulla Y, et al. Brain natriuretic peptide. A marker of myocardial dysfunction and prognosis during severe sepsis. Crit Care Med. 2004; 32: 660-5.

28. Parker MM, Shelhamer JH, Natanson C, et al. Serial cardiovascular variables in survivors and nonsurvivors of human septic shock. heart rate as an early predictor of prognosis. Crit Care Med. 1987; 15: 923-9.

29. Bernard GR, Vincent JL, Laterre PF, et al. Efficacy and safety of recombinant human activated protein C for severe sepsis. N Engl J Med. 2001; 344: 699-709.

30. Beale R, Janes JM, Brunkhorst FM, et al. Global utilization of low-dose corticosteroids in severe sepsis and septic shock: a report from the PROGRESS registry. Critical care (London, England). 2010; 14: R102.

31. Beale R, Reinhart K, Brunkhorst FM, et al. Promoting Global Research Excellence in Severe Sepsis (PROGRESS): lessons from an international sepsis registry. Infection. 2009; 37: 222-32. 